\title{
CARACTERIZAÇÃO TECNOLÓGICA PARA APROVEITAMENTO DE MATÉRIA-PRIMA SIENÍTICA COM NEFELINA
}

\author{
Carolina Del ROVERI \\ Letícia Hirata GODOY \\ Antenor ZANARDO \\ Luciano Luis da SILVA \\ Maria Margarita Torres MORENO \\ Fabiano Cabañas NAVARRO
}

\begin{abstract}
RESUMO
Rochas sieníticas com nefelina que ocorrem em Lavrinhas (SP), a $234 \mathrm{~km}$ a nordeste da cidade de São Paulo, podem constituir-se numa potencial fonte mineral para fabricação de materiais cerâmicos. Com base na mineralogia e textura dessa matériaprima, buscou-se determinar os melhores métodos de beneficiamento mineral desse corpo sienítico como fundente. Também foram realizadas análises químicas e ensaios de fusibilidade para avaliar a cor de fusão do material antes e após a separação magnética, assim como seu potencial para uso em esmaltes e engobes, comparando-se com uma amostra comercial de Nefelina padrão. Os testes preliminares mostraram que após a retirada do óxido de ferro superficial esta matéria-prima portadora de nefelina tem potencial para ser utilizada na formulação de massas de porcelanato, em substituição de outros materiais fundentes de maior valor agregado.
\end{abstract}

Palavras-chave: nefelina, óxido de ferro, caracterização petrográfica, rochas sieníticas.

\section{ABSTRACT}

TECHNOLOGICAL CHARACTERIZATION OF SYENITIC RAW MATERIAL WITH NEPHELINE FOR EXPLOITATION. Syenitic rocks with a high nepheline content near Lavrinhas (SP), $234 \mathrm{~km}$ northeast of the city of Sao Paulo, may be potentially useful for the production of ceramic products. Based on the mineralogy and texture of this raw material, the best methods of processing these syenitic rocks for fluxing properties are indicated here. In addition, chemical analyses and melting tests were carried out in order to evaluate the melting color before and after magnetic separation, as well as the potential use of this material in glazes and engobes, as compared to a Nepheline standard. Preliminary tests showed that after removal of superficial iron oxide, the raw material bearing nepheline has potential for use in the formulation of porcelain masses, replacing other fluxing materials which have higher added value.

Keywords: nepheline, iron oxide, petrographic characterization, syenitic rocks.

\section{INTRODUÇÃO}

Os minerais industriais são responsáveis por movimentar uma parcela significativa da indústria extrativa brasileira, muito embora seja uma atividade produtiva regionalizada (CPRM 2003). O Brasil dispõe de grandes depósitos, que atendem os mais diversos segmentos econômicos. As aplicações dependem de suas propriedades intrínsecas e também de seu desempenho durante as etapas de beneficiamento. As indústrias vidreira e cerâmica são as principais usuárias de nefelina sienito como matéria-prima de fundentes. Outras aplicações desse minério incluem a produção de alumina, carbonatos de sódio e potássio, cimento "portland", apatita e agregados para a construção civil, visto que essa rocha contém pouca sílica e, por isso, é tradicionalmente utilizada como brita. Na fabricação de vidros este insumo mineral é utilizado como uma fonte secundária de álcalis, uma vez que ele 
favorece o processo de vitrificação em temperaturas relativamente baixas. Já na indústria cerâmica é um substituto dos feldspatos potássicos, em função do menor preço (BAUCIA Jr. et al. 2010). A nefelina como espécime mineral é obtida comumente a partir dos nefelina sienitos, rochas ígneas praticamente livres de quartzo, ricas em feldspatos sódicos e potássicos, e com a presença de minerais ferromagnesianos, tais como piroxênios sódicos, anfibólios alcalinos e micas (GUILLET 1994). As rochas sieníticas constituem corpos intrusivos de tamanhos variados, com formas tabulares a irregulares, textura/estrutura granítica ou gnáissica e grãos que podem ser individualizados na faixa granulométrica de poucos milímetros até $100 \mu \mathrm{m}$ (CPRM 2003). O uso dos insumos minerais provenientes dos depósitos de nefelina sienitos para diversos setores industriais (com destaque para a indústria vidreira e cerâmica) é condicionado pelos teores de ferro e titânio. Os métodos de tratamento mineral normalmente utilizados para a remoção dos minerais portadores de ferro são a flotação, lixiviação e separação magnética - método mais acessível do ponto de vista econômico (BRAGA et al. 1998, FRANÇA \& SAMPAIO 2002). O êxito de cada um está relacionado à faixa granulométrica da liberação dos minerais. Para a indústria vidreira $\mathrm{o}$ teor de ferro (na forma de $\mathrm{Fe}_{2} \mathrm{O}_{3}$ ), comumente não deve ultrapassar $0,1 \%$, salvo para fabricação de vidro âmbar, onde há tolerância a teores mais elevados (HARBEN 1995). Na indústria cerâmica seguem-se os mesmos critérios de tolerância, buscando produtos de nefelina sienitos para peças cerâmicas de "queima branca".

As principais minas fornecedoras de nefelina sienitos estão localizadas no sudeste brasileiro, principalmente nas porções norte e central de Minas Gerais (MOTTA et al. 2002). Neste trabalho são apresentados os métodos de beneficiamento minerais mais eficientes para a concentração da nefelina a partir de sienitos provenientes da região de Lavrinhas - SP, município localizado cerca de 230 $\mathrm{km}$ a nordeste de São Paulo e $150 \mathrm{~km}$ a oeste do Rio de Janeiro, com base nos estudos mineralógicos e texturais. Logisticamente a localização do alvo é interessante, em função da facilidade de escoamento para os mercados consumidores de nefelina.

Os sienitos estão inseridos no contexto geológico do Maciço Alcalino de Passa Quatro, situado nos limites dos Estados de São Paulo, Minas Gerais e Rio de Janeiro. O maciço, de forma circular, ocupa área em planta de $148 \mathrm{~km}^{2}$ e é composto por várias intrusões no contexto da Província Manti- queira (Setor Central). Segundo SÍGOLO (1988) o maciço é circundado pelos complexos Juiz de Fora (gnaisse e migmatitos fortemente deformados, além de granulitos, anfibolitos, cálcio-silicáticas, quartzitos e mármores), Paraíba do Sul (gnaisses e migmatitos diversos com paleossoma gnáissico, kinzigítico, granulítico ou xistoso; mármores, xistos diversos e metabasitos) e Grupo Açungui (metassedimentos diversos). Esses complexos são cortados por importantes falhas transcorrentes de expressão regional e de idade pré-cambriana, as quais foram reativadas posteriormente durante os eventos de abertura do Atlântico e instalação do Rio Paraíba do Sul (CHIESSI 2004).

BROTZU et al. (1992) descrevem esse complexo alcalino como constituído por rochas félsicas, fortemente insaturadas, de natureza intrusiva e subvulcânica, representadas majoritariamente por nefelina sienitos e fonolitos (Figura 1). Apontam ainda a presença abundante de feldspato alcalino e seu fracionamento, juntamente com pequenas concentrações de minerais máficos, como fator preponderante para enriquecimento em nefelina.

\section{MATERIAIS E MÉTODOS}

Em função da homogeneidade das ocorrências, apenas dois fragmentos de rocha (LA e LB, Figura 2) representativos do minério foram utilizados para a confecção de duas seções delgadas (aproximadamente $30 \mu \mathrm{m}$ de espessura) para análise petrográfica. Essa análise foi realizada no Microscópio Óptico monocular Leitz (Wetzlar, Sm - Lux Pol, com aumentos de 40X, 100X, 250X e 630X) acoplado a uma câmera fotográfica digital, a partir do método de observação sob luz transmitida, no Laboratório de Laminação do Instituto de Geociências e Ciências Exatas da Universidade Estadual Paulista (UNESP) de Rio Claro. As seções delgadas foram analisadas quanto à estrutura, textura, mineralogia $\mathrm{e}$ relacionamento entre as fases presentes.

Em função da similaridade das amostras (LA e LB), foi feita uma composição de ambas. A análise granulométrica foi realizada em uma série de etapas de peneiramento a seco, por vibração mecânica, em aparelho Granutest, utilizando peneiras ABNT com aberturas correspondentes a 0,34 ; 0,$247 ; 0,18$ e $0,11 \mathrm{~mm}$. A amostra usada na análise granulométrica foi obtida a partir de cominuição prévia em moinhos de bolas por duas horas, a seco, e posterior quarteamento (quarteador Jones), gerando uma amostra de $10 \mathrm{~kg}$. A separação magnética foi realizada com um imã manual, que pos- 


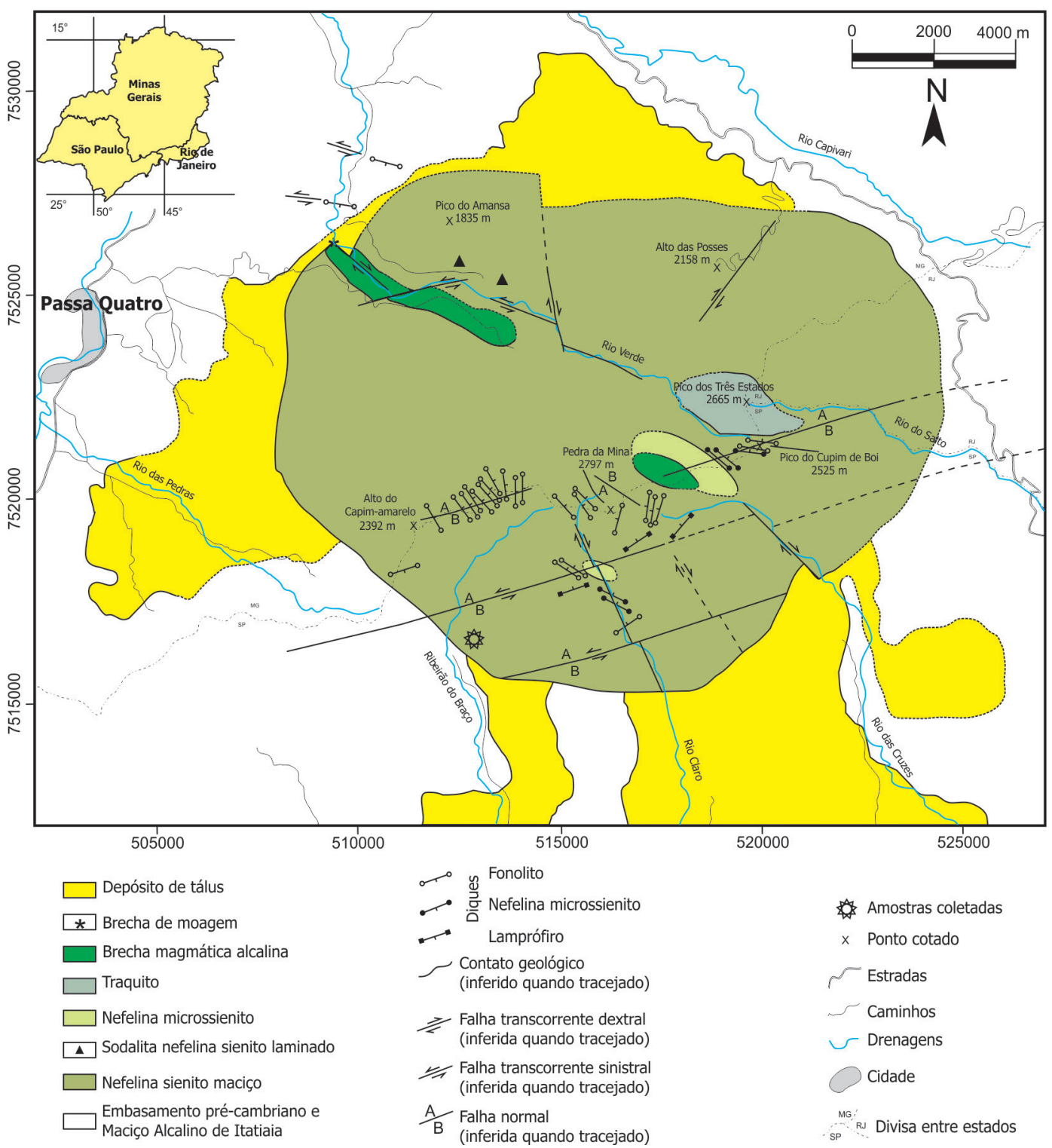

FIGURA 1 - Geologia do Maciço Alcalino de Passa Quatro e localização das rochas estudadas. Modificada de SIGOLO (1988) e CHIESSI (2004).

sui um campo magnético de cerca de 8900 Gauss (medido em laboratório). As frações foram, uma a uma, colocadas em uma bandeja, de maneira a simular a espessura de material contida em uma correia transportadora $(0,5 \mathrm{~cm}$ de espessura). Os grãos foram então expostos ao campo magnético, com o imã posicionado a cerca de $0,5 \mathrm{~cm}$ da camada de amostra. Foram realizados dez ciclos de passagem do imã pelo material, garantindo eficácia ao processo. Após a separação magnética foram quantificados os percentuais de material retido.
Análises químicas por fluorescência de raios $\mathrm{X}$ dos elementos maiores foram realizadas para 4 amostras correspondentes às seguintes frações: materiais retidos nas peneiras ABNT com aberturas de $0,247 \mathrm{~mm}, 0,18 \mathrm{~mm}$ e $0,11 \mathrm{~mm}$ e fração fina $<0,11 \mathrm{~mm}$. Essas análises tiveram o intuito de verificar principalmente o teor de $\mathrm{Fe}_{2} \mathrm{O}_{3}$ ainda contido nas amostras. As amostras foram moídas (amostra total) em moinho oscilatório até uma granulometria final inferior a $0,074 \mathrm{~mm}$. O controle de granulometria foi efetuado ao realizar peneiramento do 
material moído. As frações superiores ao desejado retornavam a mais ciclos de moagem.

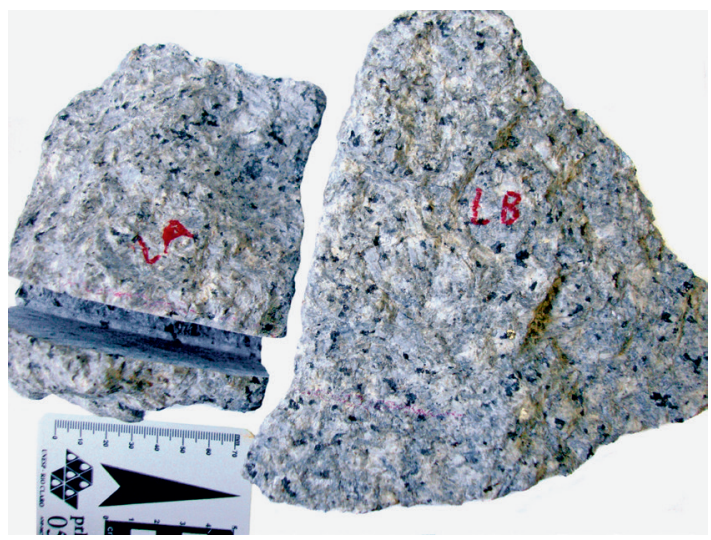

FIGURA 2 - Fragmentos de rocha utilizados para a confecção das seções delgadas.

Posteriormente as amostras foram submetidas a um processo de fusão em cadinho de grafite a $1000{ }^{\circ} \mathrm{C}$, com carbonato de estrôncio e tetraborato de lítio, em proporções exatas: $0,500 \mathrm{~g}$ de amostra, $0,300 \mathrm{~g}$ de $\mathrm{SrCO}_{3}$ e 2,700 g de $\mathrm{LiBO}_{4}$ para eliminar os efeitos da mineralogia da matriz. A partir da fusão obteve-se pastilhas vitrificadas para análises químicas em aparelho de marca Phillips modelo PW 2510, pertencente ao Laboratório de Geoquímica do Departamento de Petrologia e Metalogenia (LABOGEO/DPM) da UNESP.

Os materiais provenientes destas mesmas frações após separação magnética foram observados ao microscópio óptico, utilizando-se a técnica de preparação da lâmina com líquido de imersão (índice de refração de 1,54). Uma pequena porção de grãos provenientes de cada fração retida foi posicionada no centro na lâmina, onde se colocou o líquido de imersão, sendo a composição finalizada com a colocação da lamínula. As amostras foram analisadas em microscópio óptico à luz transmitida em aumentos de 100X, 250X e 500X.

Duas amostras representativas da fração retida na peneira com abertura de $0,11 \mathrm{~mm}$, uma sem tratamento e outra após separação magnética, foram submetidas a teste de fusão e comparadas com uma amostra padrão de nefelina importada, utilizada comumente pelos colorifícios e cerâmicas. Fragmentos do resultado da fusão do material retido nessa peneira foram analisados ao microscópio petrográfico para observação dos pontos escuros presentes no produto, por meio do pó imerso em líquido de imersão com índice de refração de 1,54.

\section{RESULTADOS E DISCUSSÕES}

\subsection{Caracterização petrográfica}

As duas amostras, denominadas LA e LB, são texturalmente similares. Tratam-se, do ponto de vista macroscópico, de rochas faneríticas, leucocráticas a hololeucocráticas de cor cinza, com pontuações submilimétricas a milimétricas de cor preta, normalmente menores que $1 \mathrm{~mm}$ (anfibólio, biotita, piroxênios e/ou opacos) e manchas milimétricas de limites difusos com tonalidade cinza claro. A estrutura observada nas duas amostras é isótropa, a textura granítica (granular hipidiomórfica) de granulação grossa e a composição eminentemente feldspática. Os maiores cristais atingem cerca de $2 \mathrm{~cm}$ e a granulação média é pouco inferior a 1 centímetro. São formadas essencialmente por feldspato alcalino e nefelina (Tabela 1).

O feldspato alcalino (Figura 3A, B, C, D, E, F) ocorre sob a forma de cristais tabulares a irregulares que atingem mais de $1 \mathrm{~cm}$ de comprimento, possuem geminação Carlsbad e são constituídos por feldspato potássico intercrescido com feldspato sódico (mesopertita mal definida por desmisturação de anortoclásio) (Figura 3D). Intersticialmente podem ocorrer pequenos cristais de albita, praticamente límpidos, de formação tardia (Figura 3A) $\mathrm{e}$, localmente, pseudomorfos de leucita (formas arredondadas com faces de trapezoedro), constituídos basicamente por feldspatos de granulação fina salpicados por pontuações de material opaco. Os cristais de feldspatos são ricos em inclusões fluidas e sólidas. A nefelina constitui cristais de tamanho médio a pequeno (normalmente menores que $5 \mathrm{~mm}$ ), anedrais, dispostos intersticialmente, com grau variado de alteração (incipiente a total) para zeólitas, mica branca e cancrinita (Figura 3E, F).

A hornblenda constitui cristais anedrais a subedrais, irregulares a subtabulares, normalmente menores que $4 \mathrm{~mm}$, embora forme agregados com diâmetros maiores que $5 \mathrm{~mm}$ com outros minerais máficos (Figura 3B, C). Exibe cor marrom escuro em $\gamma$ e $\beta$ e amarelo forte em $\alpha$, cor verde na borda, a qual apresenta evidências de corrosão magmática, com cordões ou filetes constituídos por minúsculos cristais opacos. Localmente, aparece envolvendo e substituindo clinopiroxênio (augita). A augita mostra-se como pequenos cristais anedrais parcialmente substituídos por hornblenda, onde, normalmente, estão inclusos.

Os minerais opacos formam cristais minúsculos a pequenos (em todos os casos observados menores que $1 \mathrm{~mm}$ ), anedrais a subedrais, disper- 
TABELA 1 - Composição modal estimada (\% em volume) das amostras LA e LB.

\begin{tabular}{lcc}
\hline Composição mineralógica & Amostra LA & Amostra LB \\
\hline Feldspato alcalino & $( \pm 75,5 \%)$ & $( \pm 71,4 \%)$ \\
Nefelina + material de alteração & $( \pm 9,8 \%)$ & $( \pm 14,3 \%)$ \\
Hornblenda & $( \pm 4,9 \%)$ & $( \pm 2,9 \%)$ \\
Minerais opacos & $( \pm 1,5 \%)$ & $( \pm 1,4 \%)$ \\
Titanita & $( \pm 1,5 \%)$ & $( \pm 1,4 \%)$ \\
Analcima/fluorita (?) & $( \pm 1,0 \%)$ & $( \pm 1,9 \%)$ \\
Pseudomorfos de leucita & $( \pm 1,0 \%)$ & $( \pm 1,0 \%)$ \\
Mica branca & $( \pm 1,0 \%)$ & $( \pm 1,0 \%)$ \\
Carbonato & $( \pm 1,0 \%)$ & $( \pm 1,0 \%)$ \\
Apatita & $(<1,0 \%)$ & $(<1,0 \%)$ \\
Biotita & $(<1,0 \%)$ & $(<1,0 \%)$ \\
Augita & $(<1,0 \%)$ & $($ Traços) \\
Cancrinita & $($ Traços) & $( \pm 1,0 \%)$ \\
Zeólita & $($ Traços) & $( \pm 1,0 \%)$ \\
Zircão e melanita & -- & $($ Traços) \\
\hline
\end{tabular}

sos pela secção de forma mais ou menos homogênea, porém em quantidade e dimensões maiores em associação com os minerais máficos (hornblenda, titanita, biotita e piroxênio). São frequentes as inclusões de minúsculos cristais no interior dos feldspatos com espaçamento médio submilimétrico.

A titanita constitui cristais pequenos a minúsculos (normalmente menores que $2 \mathrm{~mm}$ ) e tamanho médio inferior a $400 \mu \mathrm{m}$. Ocorre dominantemente associada aos máficos e opacos (Figura $3 \mathrm{~B}, \mathrm{C})$, embora apareça como cristais pequenos a muito pequenos, dispostos de forma isolada, inclusos no feldspato. A biotita forma cristais pequenos e isolados, principalmente em associação com a hornblenda e opacos. O carbonato forma minúsculas pontuações e pequenos cristais anedrais dispostos intersticialmente, principalmente salpicando os feldspatos. A analcima ocorre intersticialmente corroendo o feldspato e a nefelina. A apatita aparece como pequenos cristais prismáticos a irregulares inclusos em outros minerais e, em maior quantidade, quando associados com os opacos. A cancrinita forma cristais pequenos e se associa à zeólita nos produtos de transformação da nefelina. $\mathrm{O}$ zircão forma concentrações difusas de pequenos cristais, euedrais a anedrais, prismáticos curtos, com dimensões menores que 100 $\mu \mathrm{m}$. A melanita foi observada na forma de um pequeno cristal anedral.
As duas amostras, LA e LB, são rochas de origem magmática plutônica de natureza alcalina insaturada em sílica e classificadas, respectivamente, como hornblenda nefelina sienito e nefelina sienito. Inicialmente ocorreu a cristalização das fases leucita e augita, substituídas, respectivamente, por feldspato e hornblenda. Na sequência ocorreu a cristalização da hornblenda e anortoclásio; o primeiro parou de cristalizar e foi corroído durante os estágios finais da cristalização do anortoclásio. Nefelina e biotita, titanita e minerais opacos de granulação fina encerraram a cristalização magmática. Na fase tardia pós-cristalização magmática houve a formação de analcima e/ou fluorita, a desmisturação do anortoclásio gerando antipertita, o crescimento intersticial de albita e a alteração da nefelina para cancrinita e zeólita. A distribuição e o posicionamento dos minúsculos cristais opacos e da titanita impossibilitariam a remoção total destas fases, mesmo com a moagem na faixa granulométrica abaixo de $40 \mu \mathrm{m}$. Porém, na moagem com granulometria abaixo de 200 ou $100 \mu \mathrm{m}$, parece ser possível retirar mais de $90 \%$ do ferro e titânio presentes, por processo gravimétrico combinado com magnético. A única peculiaridade da amostra LB em relação à LA é o fato dela conter menor quantidade de máficos, pouco mais de nefelina e apresentar concentração localizada de pequenos cristais de zircão. 

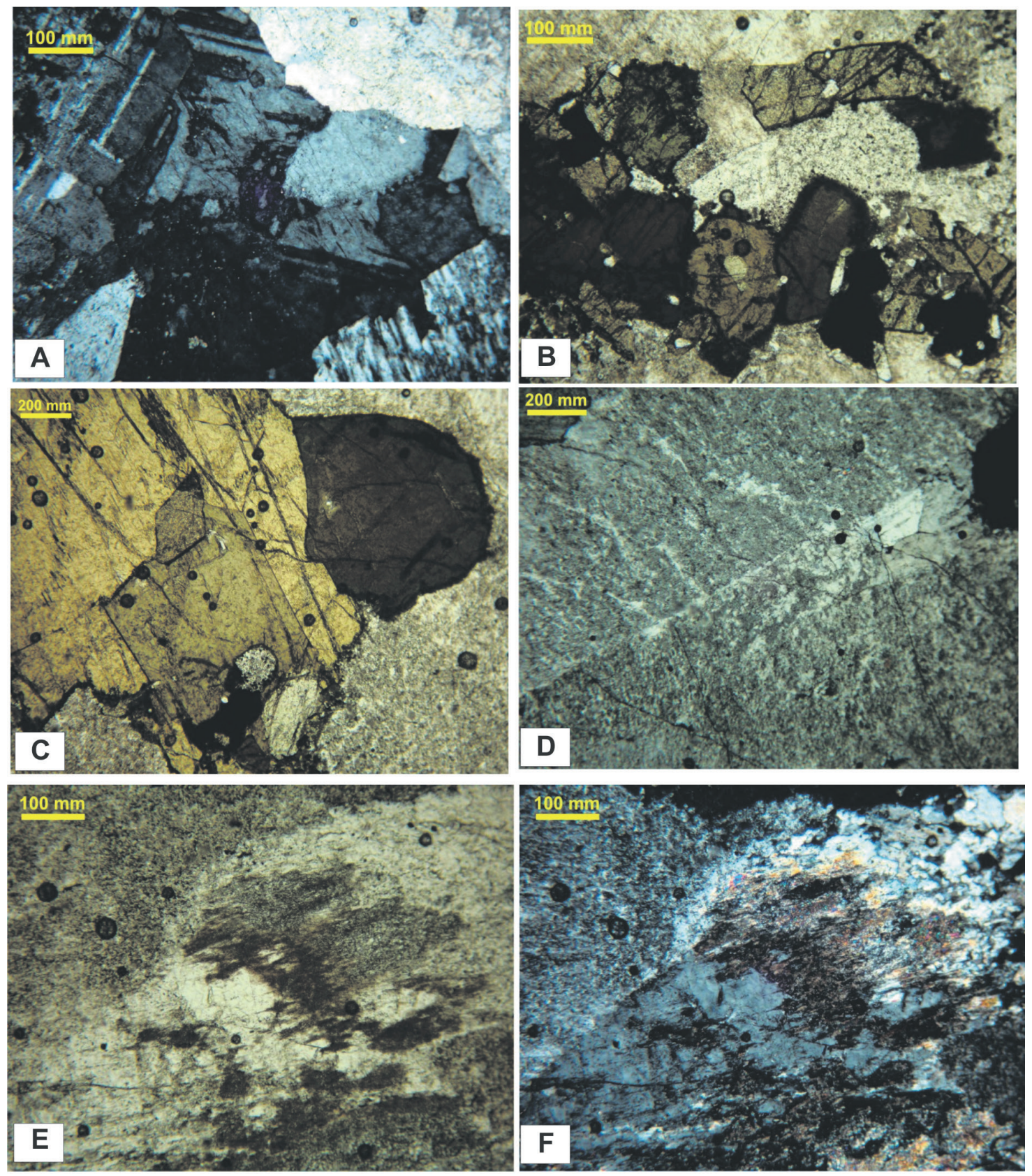

FIGURA 3 - Fotomicrografias das amostras LA e LB, sob luz transmitida. (A) Geminação típica de albita entre cristais de feldspato potássico (nicóis cruzados). (B) Porção da seção rica em máficos (hornblenda, opacos e titanita) (nicóis cruzados). (C) Cristais de hornblenda, titanita e magnetita inclusa na hornblenda, envoltos por feldspato de aspecto turvo (nicóis cruzados). (D) Feldspato potássico com geminação Carlsbad e filetes/vênula de manchas de albita (nicóis cruzados). (E) Cristal de nefelina parcialmente alterado para cancrinita e zeólita, envolto por feldspato alcalino, sob nicóis paralelos e (F) sob nicóis cruzados, onde nota-se a cancrinita (porção com birrefringência moderada a forte). 


\subsection{Análise granulométrica}

A análise granulométrica do material cominuído (composição de LA e LB), representativo da rocha fresca, teve por finalidade identificar todas as frações do material e as faixas preferenciais de concentração de minerais pesados e/ou opacos (principalmente os portadores de ferro). Grande parte do material passa pela peneira com abertura $0,11 \mathrm{~mm}$ $(28,6 \%)$, enquanto há distribuição homogênea entre 0,247 e $0,110 \mathrm{~mm}$, e um ligeiro aumento para a granulometria mais fina - respectivamente $20,5 \%$ $(0,247), 21,5 \%(0,18)$ e $22,5 \%(0,11)-$, apesar de apenas $6,2 \%$ ficarem retidos na peneira $0,34 \mathrm{~mm}$ (Tabela 2, Figura 4). Isto mostra que o material, após a moagem preliminar, apresenta alto percentual de finos.

\subsection{Separação magnética}

A partir das alíquotas $(100 \mathrm{~g})$ provenientes do quarteamento de todas as frações granulométricas anteriormente definidas no peneiramento a seco, observou-se que a proporção de material magnético diminui até o material retido na peneira com abertura $0,18 \mathrm{~mm}$ e volta a aumentar nas porções mais finas (Tabela 3, Figura 5). Isto ocorre em função de alguns fatores, como a relação entre o tamanho das partículas, respectivas massas e dimensões

TABELA 2 - Distribuição granulométrica. Massa inicial: $10 \mathrm{Kg}$.

\begin{tabular}{cc}
\hline $\begin{array}{c}\text { Abertura nominal das } \\
\text { peneiras }(\mathrm{mm})\end{array}$ & Massa retida $(\%)$ \\
\hline $0,34(>\# 32)$ & 6,2 \\
$0,247(\# 42)$ & 20,5 \\
$0,18(\# 60)$ & 21,5 \\
$0,11(\# 100)$ & 22,5 \\
Fundo $(<\# 100)$ & 28,6 \\
\hline
\end{tabular}

dos agregados que são constituídos por minerais máficos associados à magnetita. Esta relação diminui o arraste de partículas não magnéticas ou muito pouco magnéticas pelas magnéticas durante a separação a seco. Nas frações mais grossas as partículas magnéticas estão liberadas e contêm maior quantidade de material não magnético, bem como a massa não permite que as minúsculas partículas magnéticas e/ou com minerais muito pouco magnéticos contidas nos grãos consigam carregá-las para a fração magnética. Já na fração mais fina, a diminuta massa dos grãos possibilita maior arraste das partículas não magnéticas pelas magnéticas e, além disso, ocorre a concentração dos minerais mais densos e magnéticos nesta fração. Este aspecto pode ser minimizado por um processo de separação magnética a úmido. As frações magnéticas contêm uma quantidade razoável de fragmentos onde minerais máficos e/ou magnéticos não são observados, enquanto na fração não magnética os minerais máficos são mais evidentes (ferro-magnesianos e/ou titaníferos), evidenciando que a separação pode ser

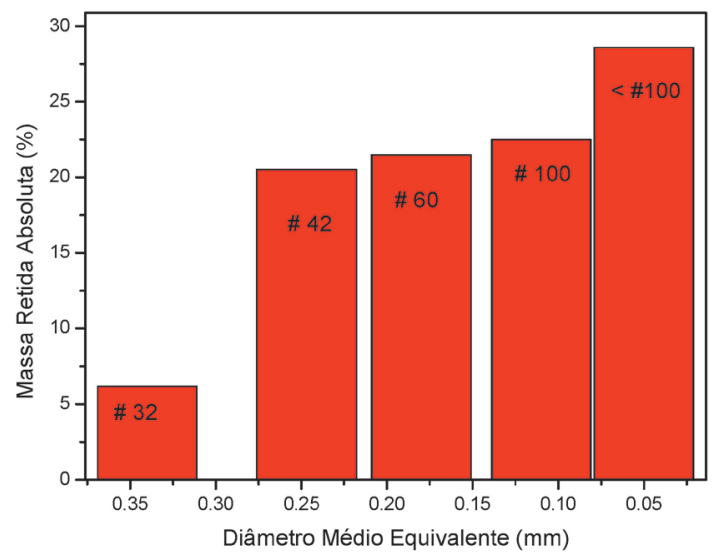

FIGURA 4 - Distribuição granulométrica do material em cada peneira (\%): diâmetro médio equivalente de 0,$34 ; 0,247 ; 0,18$ e $0,11 \mathrm{~mm}$ e menor que $0,11 \mathrm{~mm}$ (fundo).

TABELA 3 - Distribuição granulométrica do material submetido à separação com imã de mão.

\begin{tabular}{cccc}
\hline $\begin{array}{c}\text { Abertura Nominal das } \\
\text { Peneiras }(\mathrm{mm})\end{array}$ & $\begin{array}{c}\text { Massa Inicial } \\
(\mathrm{g})\end{array}$ & Massa Retida pelo Ímã $(g)$ & $\begin{array}{c}\text { Massa Retida pelo Ímã } \\
(\%)\end{array}$ \\
\hline $0,34(>\# 32)$ & 100 & 28,112 & 28,11 \\
$0,247(\# 42)$ & 100 & 26,054 & 26,05 \\
$0,18(\# 60)$ & 100 & 15,160 & 15,16 \\
$0,11(\# 100)$ & 100 & 23,497 & 23,50 \\
Fundo $(<\# 100)$ & 100 & 38,970 & 38,97 \\
\hline
\end{tabular}




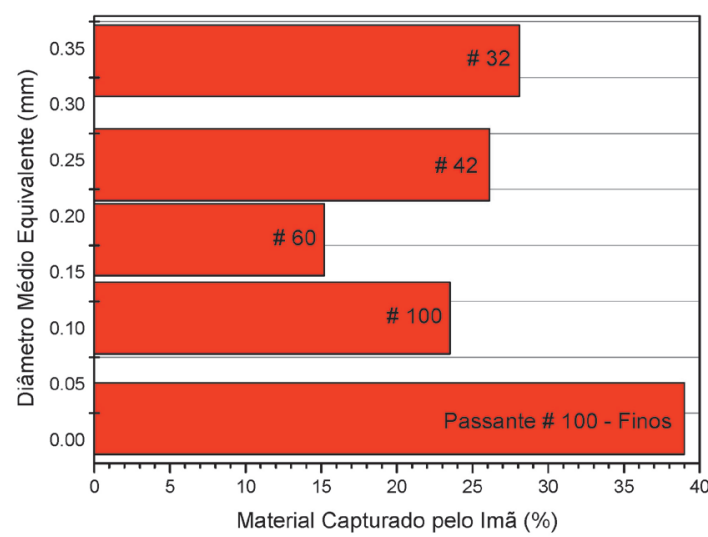

FIGURA 5 - Distribuição granulométrica do material magnético.

melhorada com um processo a úmido (com fluxo de água), associado a uma separação gravimétrica.

3.4 Análise química das frações selecionadas após separação magnética

A tabela 4 ilustra os resultados das análises químicas de elementos maiores para as cinco frações selecionadas após a separação magnética: acima de 0,$34 ; 0,247 ; 0,18$ e $0,11 \mathrm{~mm}$ e menor que $0,11 \mathrm{~mm}$ (finos). Estas frações foram escolhidas em função de seu interesse do ponto de vista comercial. As análises das frações são comparadas com a média da composição química das amostras LA e LB sem separação (Tabela 5).

A composição química média das amostras LA e LB apresenta menor teor de sílica e maior teor de ferro em relação às amostras das frações selecionadas, mostrando que a separação magnética foi eficiente. As amostras das frações apresentam composição geral bastante similar; os teores que variam estão diretamente relacionados com a separação magnética, e correspondem aos óxidos/ silicatos de ferro e titânio. Na fração fina o teor de $\mathrm{Fe}_{2} \mathrm{O}_{3}$ é ainda bastante elevado, mesmo após a separação magnética. Isto ocorre porque a eficiência da separação magnética a seco com distância constante do imã em relação à partícula diminui em especial para os fragmentos com minerais levemente magnéticos (paramagnéticos), correspondentes aos silicatos com ferro, magnésio e titânio.

A análise petrográfica também sugere que a maior cominuição possibilita melhor liberação dos minerais paramagnéticos e/ou máficos que ocorrem associados aos ferrimagnéticos (magnetita e ilmenita), dificultando a separação de anfibólios, biotita, piroxênio, titanita, hematita e hidróxidos de ferro dos minerais diamagnéticos (feldspatos, nefelina, zeólita). Comparando a separação granulométrica com os resultados químicos constata-se que o maior rendimento na captura de minerais portadores de ferro e titânio ocorreu nas frações do material retido nas peneiras de aberturas 0,247 e $0,18 \mathrm{~mm}$. Nestas frações, os grãos magnéticos apresentam tamanho suficiente para serem atraídos pelo imã e arrastam menor quantidade de material diamagnético. Em especial, na fração retida em peneira com abertura $0,18 \mathrm{~mm}$, ocorre a perda de apenas $15,16 \%$ da massa, enquanto a retirada de ferro e titânio foi mais eficiente na fração de $0,247 \mathrm{~mm}$. Todavia, cabe ressaltar que nesta fração é impossí-

TABELA 4 - Análise química de elementos maiores das amostras selecionadas por fluorescência de raios X (\% em peso).

\begin{tabular}{ccccccccccccc}
\hline Amostra & $\mathrm{SiO}_{2}$ & $\mathrm{TiO}_{2}$ & $\mathrm{Al}_{2} \mathrm{O}_{3}$ & $\mathrm{Fe}_{2} \mathrm{O}_{3}$ & $\mathrm{MnO}$ & $\mathrm{MgO}$ & $\mathrm{CaO}$ & $\mathrm{Na}_{2} \mathrm{O}$ & $\mathrm{K}_{2} \mathrm{O}$ & $\mathrm{P}_{2} \mathrm{O}_{5}$ & $\mathrm{PF} *$ & Soma \\
\hline \# 42 & 62,98 & 0,23 & 19,31 & 0,56 & 0,05 & 0,07 & 0,57 & 7,11 & 7,86 & 0,02 & 1,25 & 100,01 \\
\# 60 & 62,94 & 0,29 & 19,23 & 0,64 & 0,06 & 0,11 & 0,68 & 6,95 & 7,81 & 0,03 & 1,26 & 100,00 \\
\# 100 & 62,37 & 0,64 & 19,03 & 1,01 & 0,11 & 0,27 & 1,11 & 6,97 & 7,71 & 0,05 & 0,74 & 100,01 \\
Finos & 60,18 & 1,02 & 19,32 & 1,92 & 0,20 & 0,57 & 1,73 & 6,97 & 7,30 & 0,12 & 0,67 & 100,00 \\
\hline
\end{tabular}

$* \mathrm{PF}=$ Perda ao Fogo

TABELA 5 - Composição química média por fluorescência de raios X das amostras LA e LB antes da separação granulométrica e sem separação magnética (\% em peso).

\begin{tabular}{ccccccccccccc}
\hline Amostra & $\mathrm{SiO}_{2}$ & $\mathrm{TiO}_{2}$ & $\mathrm{Al}_{2} \mathrm{O}_{3}$ & $\mathrm{Fe}_{2} \mathrm{O}_{3}$ & $\mathrm{MnO}$ & $\mathrm{MgO}$ & $\mathrm{CaO}$ & $\mathrm{Na}_{2} \mathrm{O}$ & $\mathrm{K}_{2} \mathrm{O}$ & $\mathrm{P}_{2} \mathrm{O}_{5}$ & $\mathrm{PF}^{*}$ & Soma \\
\hline Média* & 59,24 & 0,89 & 18,96 & 3,06 & 0,21 & 0,51 & 1,59 & 6,38 & 7,47 & 0,11 & 1.58 & 100,00 \\
\hline
\end{tabular}

$* \mathrm{PF}=$ Perda ao Fogo 
vel, em vista da intensidade de campo magnético aplicado, retirar as micropontuações de óxidos e hidróxidos (Fe, Ti e/ou Mn) nos feldspatos, pseudomorfos de leucita, nefelina e zeólita, que devem corresponder a pouco menos de $0,5 \%$ do peso total.

3.5 Microscopia das frações selecionadas após separação magnética

As frações submetidas à separação magnética foram observadas em microscópio óptico, em lâmina com líquido de imersão (com índice de refração de 1,54). Foram contados trinta grãos em cada amostra, buscando identificar principalmente a ocorrência de opacos como inclusões. Os resultados provenientes da contagem de 30 grãos em cada amostra estão apresentados na tabela 6. Observouse que há opacos na forma de minúsculas inclusões principalmente em grãos de feldspato e nefelina, fato que explica o ainda elevado teor de ferro mesmo após separação magnética. Conforme será discutido no tópico seguinte (3.6), após a fusão das amostras observaram-se fragmentos das pontuações negras (Figura 8). Também pôde ser constatado que nas frações mais finas ocorre maior liberação de titanita, minerais máficos e magnetita, que normalmente formam agregados de dimensões médias entre 1- $2 \mathrm{~mm}$, até quase $1 \mathrm{~cm}$ no maior diâmetro. $\mathrm{O}$ isolamento da magnetita destes agregados dificulta a remoção da titanita e dos silicatos portadores de ferro e magnésio dos minerais alcalinos sem ferro e magnésio (feldspato, nefelina, zeólita, cancrinita).
3.6 Ensaios de fusão e microscopia óptica do material fundido

Os cones de queima gerados a partir da fusão das amostras passantes na malha $0,11 \mathrm{~mm}$ sem e após separação magnética foram comparados com uma amostra padrão de nefelina importada (comumente utilizada pelos colorifícios e cerâmicas). Esta fração foi escolhida para o teste pelo fato dos teores de ferro e titânio estarem próximos entre as duas frações com o melhor desempenho após tratamento por concentração magnética, como também pela fácil visualização dos efeitos causados pelos minerais portadores de ferro no fundido.

Os cones de queima gerados com as matérias-primas sem e após tratamento de separação magnética e com a nefelina padrão, bem como aqueles usados para o teste de binil, mostraram os seguintes resultados: (1) o cone da amostra padrão apresentou coloração branca no cone de queima e transparente no teste de binil, enquanto os das matérias-primas, coloração cinza escura, com pontuações escuras em matriz mais clara, (2) o cone da amostra tratada (após separação magnética) apresentou cor um pouco mais clara que a não tratada, porém sem grande contraste. Os aspectos superficiais dos testes podem ser verificados nas figuras 6 (ensaio do cone) e 7 (teste de binil). Nota-se também que a amostra padrão apresenta melhor fusibilidade que as amostras tratadas, como atestado pela forma do cone (Figura 6).

TABELA 6 - Composição mineralógica das faixas granulométricas dos produtos magnéticos. Método de contagem de grãos ao microscópio (\%).

\begin{tabular}{|c|c|c|c|c|}
\hline Minerais & $\begin{array}{c}\text { Quantidade } \\
\text { observada na } \\
\text { Amostra Finos } \\
\text { (peneira }<0,11)\end{array}$ & $\begin{array}{c}\text { Quantidade } \\
\text { observada na } \\
\text { Amostra peneira } \\
0,247\end{array}$ & $\begin{array}{c}\text { Quantidade } \\
\text { observada na } \\
\text { Amostra peneira } \\
0,18\end{array}$ & $\begin{array}{c}\text { Quantidade } \\
\text { observada na } \\
\text { Amostra peneira } \\
0,11\end{array}$ \\
\hline Feldspato alcalino & 27,45 & 20,45 & 33,33 & 24,44 \\
\hline Nefelina & 13,73 & 9,09 & 12,82 & 13,33 \\
\hline Opacos (livres) & 5,88 & 11,36 & 10,26 & 11,11 \\
\hline Opacos (inclusões) & 7,84 & 11,36 & 10,26 & 13,33 \\
\hline Titanita & 3,92 & 2,27 & 0,00 & 2,22 \\
\hline Zeólita & 3,92 & 6,82 & 0,00 & 4,44 \\
\hline Carbonatos & 9,80 & 4,55 & 7,69 & 4,44 \\
\hline Mica & 9,80 & 11,36 & 7,69 & 8,89 \\
\hline Hornblenda & 15,69 & 20,45 & 17,95 & 15,56 \\
\hline Zircão & 1,96 & 2,27 & 0,00 & 2,22 \\
\hline
\end{tabular}




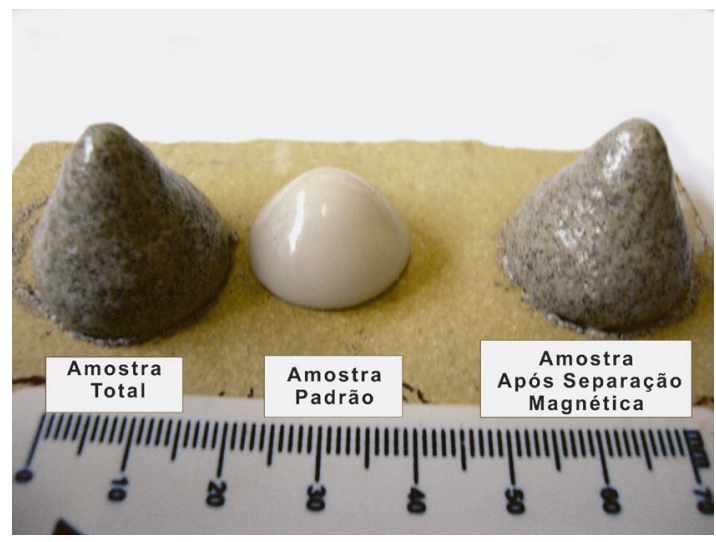

FIGURA 6 - Teste do cone para as amostras total, padrão e tratada.

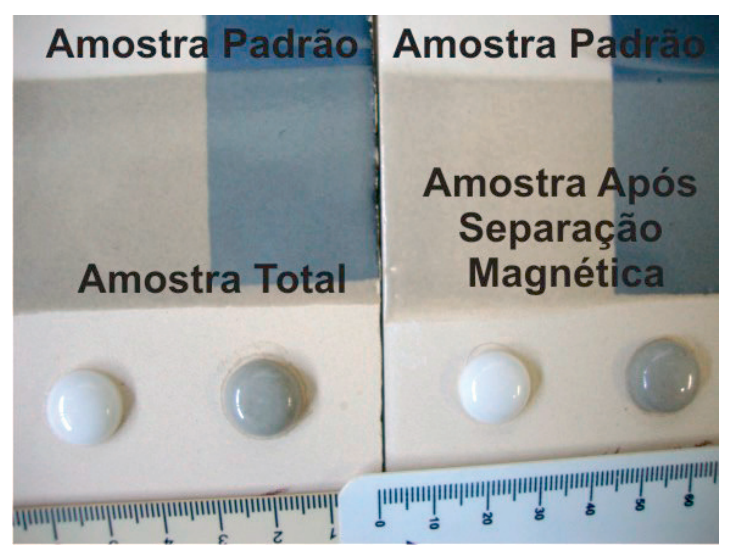

FIGURA 7 - Teste de binil das amostras total e tratada (após separação magnética). Foram usadas duas bases para ensaio: clara (simulando base cerâmica clara) e escura (simulando base cerâmica avermelhada ou marrom). Os botões claros representam a amostra padrão e os botões escuros, as amostras total e após separação magnética.

Para detectar a natureza das pontuações escuras foram obtidos fragmentos do cone produzido com a amostra tratada, os quais foram pulverizados e acondicionados em líquido de imersão com índice de 1,55 para análise de microscopia sob luz transmitida. A análise mostrou que os fragmentos apresentam sinais de dissolução e estão envoltos por vidro, de aspecto límpido, porém os restos de feldspatos, que representam pouco mais de $50 \%$, exibem aspecto turvo em função de grande quantidade de microcavidades e microinclusões opacas de aspecto pulverulento (Figura $8 \mathrm{~A}, \mathrm{~B}, \mathrm{C}, \mathrm{D}, \mathrm{F}, \mathrm{G}, \mathrm{H}$ e I). Como contaminantes, observou-se a presença de grãos de titanita inclusos em feldspatos, mais raramente isolados (Figura $8 \mathrm{E}$, F e I), pontuações de minerais opacos inclusos em feldspatos e minerais máficos contidos em feldspato, bem como isolados (liberados).

No material vítreo observa-se localmente a presença de microcristais fibrosos, aparentemente de piroxênio alcalino, dispostos em difusos flocos, às vezes com distribuição fibrorradial, sugerindo terem se cristalizado durante a fusão (Figura $8 \mathrm{G}$ ). Um aspecto que chama a atenção no material vítreo é a presença de minúsculos corpos esféricos de material isótropo (vítreo), de cor amarelo amarronzado pálido, com índice de refração superior ao do material vítreo amplamente dominante, que é incolor ao aumento microscópico (Figura 8H e I). Este aspecto aparenta resultar da fusão de material máfico, gerando líquido com propriedades reológicas diferentes do vidro dominante (resultante da fusão de nefelina, albita e feldspato potássico). Isto faz com que se leve certo tempo para que ocorra a homogeneização, desta forma, restando gotículas de vidro mais denso e, possivelmente, menos viscoso no vidro dominante.

Outro aspecto observado é que a nefelina, zeólita e quase toda a albita foram consumidas na fusão, restando feldspatos potássicos e titanita (mineral com menor grau de reação de fusão), que constitui fase possivelmente gerada a partir da fusão de minerais máficos. Os minerais máficos foram quase todos consumidos no processo de fusão. Os restos de feldspato mostram aspecto turvo ao microscópio em grau variado, com vários grãos apresentando aspecto quase opaco, resultante da grande quantidade de microporos com gases e minúsculas pontuações opacas terrosas possivelmente constituídas por microcristais de minerais máficos e óxidos de ferro, titânio e/ou manganês. Esta observação mostra que a maior parte das pontuações escuras corresponde a grãos de feldspatos potássico com maiores quantidades de micro inclusões pulverulentas e poros. Portanto, as pontuações escuras não são formadas apenas por minerais máficos e/ou opacos. A maior quantidade de microbolhas geradas durante a fusão está associada a restos de feldspato, aparentemente em sua superfície, sugerindo que são geradas principalmente pela liberação de gases presentes nesta fase mineral (inclusões fluidas, carbonatos, filossilicatos microcristalinos e zeólita). Cabe ressaltar que a limpidez do fundido, em relação aos restos de feldspatos, sugere que a fusão total resultará em material de tonalidade bem mais clara e com número de pontuações escuras muito menores ou mesmo ausentes em temperaturas mais altas, no caso de total homogeneização. Ressalta-se, no entanto, que vidro incolor ou praticamente incolor parece não ser possível de ser obtido apenas com processos de beneficiamento tradicionais, envolvendo separação magnética, separação por densidade e/ou flotação. 

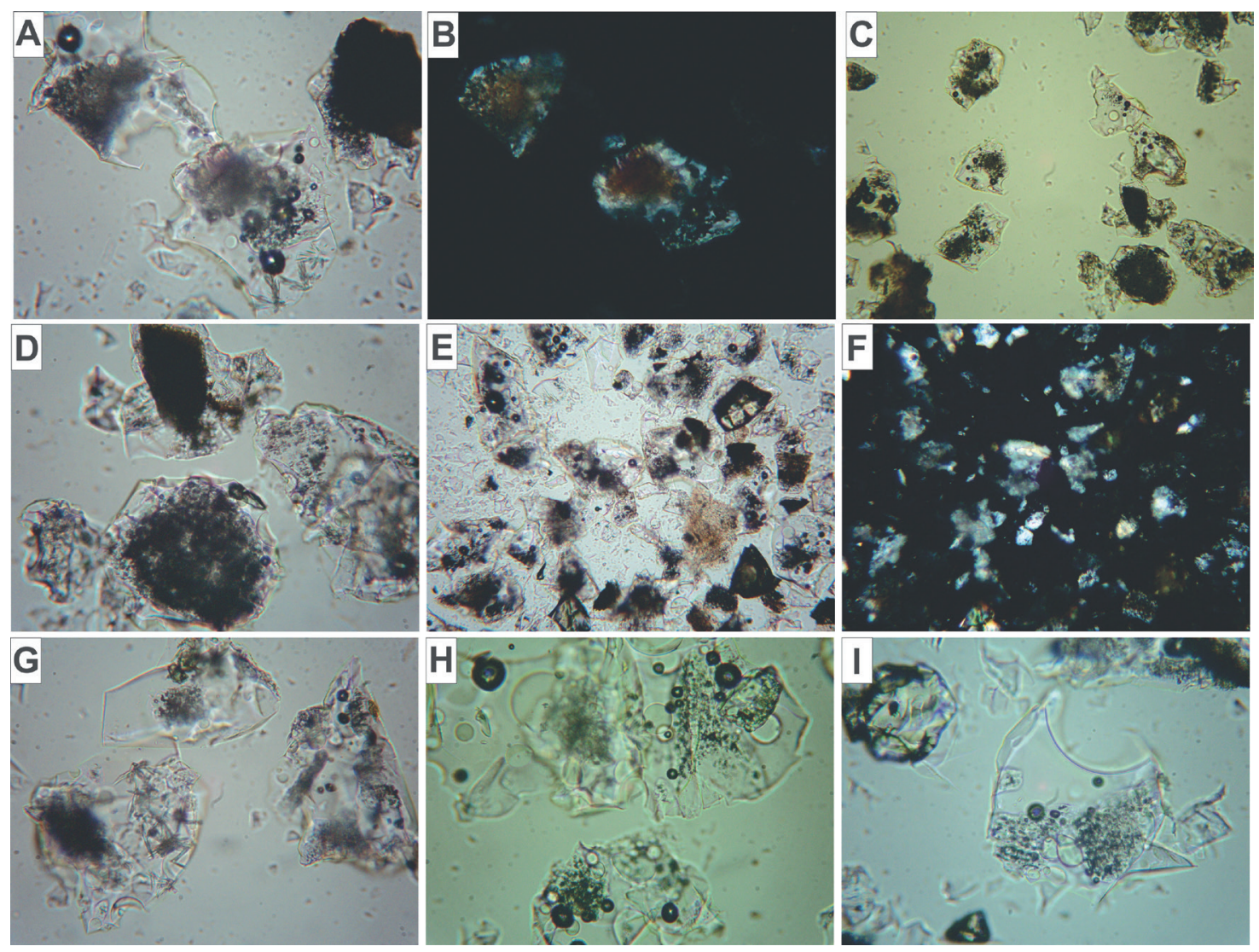

FIGURA 8 - Petrografia das pontuações negras oriundas da fusão. As imagens se referem ao aumento de 200X. (A) Restos de feldspatos, que representam pouco mais de $50 \%$ da fração, exibem aspecto turvo em função de grande quantidade de microcavidades e micro inclusões opacas de aspecto pulverulento; o vidro resultante é relativamente límpido, observado sob nicóis paralelos e (B) nicóis cruzados; (C) Grãos de feldspato potássico com quantidades maiores de microinclusões pulverulentas e poros (pontuações escuras), sob nicóis paralelos; (D) Detalhe das minúsculas pontuações opacas terrosas possivelmente constituídas por microcristais de minerais máficos e óxidos de ferro, titânio e/ou manganês em grãos de feldspatos, sob nicóis paralelos; (E) Visão mais geral do campo da imagem anterior, onde é possível observar titanita de relevo mais alto, sob nicóis paralelos e (F), sob nicóis cruzados, destacando os cristais de titanita; (G) Observação da presença de micro cristais fibrosos, aparentemente de piroxênio alcalino, dispostos em difusos flocos, às vezes com distribuição fibro-radial, sugerindo ter-se cristalizado durante a fusão; $(\mathrm{H})$ Presença de minúsculos corpos esféricos de material isótropo (vítreo), resultante da fusão de material máfico, gerando gotículas de vidro mais denso e, possivelmente, menos viscoso no vidro dominante; (I) Detalhe das gotículas de vidro de índice de refração maior que o vidro dominante e com leve cor acastanhada.

\section{CONSIDERAÇÕES FINAIS}

Os trabalhos realizados mostram que o sienito da região de Lavrinhas é rico em feldspatos alcalinos (ortoclásio e albita), contendo nefelina em porcentagem menor que $15 \%$. Estes minerais, em especial o feldspato potássico, contêm minúsculas inclusões de opacos pulverulentos, titanita, carbonato, sericita e possivelmente zeólita e argilominerais, além de microporos preenchidos por fluidos.
No interior dos feldspatos e pseudomorfos de leucita as micropontuações opacas frequentemente possuem espaçamento médio da ordem de $50 \mu \mathrm{m}$. Já os agregados máficos que contêm hornblenda, magnetita, titanita, biotita e outros minerais com ferro, titânio ou magnésio possuem dimensões milimétricas a submilimétricas (normalmente menores que 6 $\mathrm{mm}$ ), com espaçamento sub-milimétrico a centimétrico. Estas feições, associadas à dimensão média da magnetita $(<300 \mu \mathrm{m}$, até sub-micrométricas), 
permitem projetar uma granulometria ideal de moagem na faixa de 0,3 a $0,10 \mathrm{~mm}$ para separar as fases portadores de ferro e titânio por magnetismo.

A moagem em faixas granulométricas inferiores provoca maior liberação de cristais com muito baixo ou sem magnetismo (titanita e minerais máficos), prejudicando o rendimento na retirada de ferro e titânio por separação magnética. Os resultados dos ensaios evidenciam que é necessário algum tratamento adicional à separação magnética para a retirada efetiva de ferro do material. Nas frações mais finas, por exemplo, a massa diminuta dos grãos magnéticos possibilita um maior arraste das partículas não magnéticas. Este aspecto pode ser minimizado por processo de separação magnética a úmido.

Os resultados dos ensaios de fusão mostram que o material pode ser utilizado na fabricação de vidro, em especial âmbar, e se apresenta como uma fonte potencial de fundente para uso em massas de porcelanato. Cabe ressaltar que o produto final, após a fusão em temperaturas mais altas, resultará em material de tonalidade bem mais clara, com número reduzido de pontuações escuras. Para que se tenha total homogeneização, resultando em vidro incolor ou praticamente incolor, são necessários processos adicionais de beneficiamento mineral.

Um teste de beneficiamento envolvendo métodos específicos de separação gravimétrica e magnética a úmido, com correias ou rolos, seria interessante, para verificar o aumento de eficiência de retirada do ferro. O método magnético a seco mostrou-se mais efetivo em granulometria de moagem superior a $100 \mu \mathrm{m}$, apesar da moagem realizada conter uma concentração dos minerais máficos na fração menor que $100 \mu \mathrm{m}$, em função da natureza textural e reológica dos minerais. Essa fração teve a maior quantidade de material retirada pelo ímã e, mesmo assim, ficou com os teores mais elevados de ferro e titânio. Os resultados sugerem que a eficiência para retirar os elementos cromóforos ( $\mathrm{Fe}, \mathrm{Ti}$ e $\mathrm{Mn}$ ) pode ser bem mais efetiva quando a separação é realizada de acordo com classes granulométricas, combinada com separações magnética a úmido/seco e por densidade e/ou flotação. Esse último método é o mais recomendado para as frações de granulação mais fina, pela eficaz liberação da magnetita dos agregados de minerais ferromagnesianos e titanita, dificultando a retirada dos elementos cromóforos contidos nos ferromagnesianos de magnetismo muito baixo. Os minerais ferromagnesianos e a titanita são mais densos que o feldspato, nefeli- na e zeólita e podem ser separados por processos gravimétricos a úmido ou a seco e/ou flotação. As frações granulométricas mais grossas após serem submetidas à separação combinada (magnética, gravimétrica e/ou flotação) podem ser moídas em granulação mais fina e submetidas novamente ao processo combinado de separação. Desta forma, acredita-se que é possível atingir teores de ferro e titânio inferiores a $0,1 \%$, ou pouco superior a este valor. Todavia não tivemos condições técnicas para testar estas hipóteses.

O beneficiamento mineral utilizando o método magnético com várias intensidades, gravidade e/ou flotação para as diferentes classes granulométricas geradas na moagem pode propiciar a obtenção de um produto com características que permitam a sua utilização na produção de vidro claro ou transparente, bem como na produção de fritas. Material com estas características pode ser obtido a partir das frações entre 0,1 e $0,3 \mathrm{~mm}$. O refino da separação do material utilizando mais de um ciclo de moagem e de separação combinada pode gerar teores de elementos cromóforos inferiores a $0,1 \%$, porém com baixo rendimento em relação à quantidade inicial (possivelmente menos de 25\%). Ainda assim não se garante a possibilidade de uso na composição do engobe, em função do observado no resultado do teste de fusão. Já na produção de fritas, onde ocorre a fusão total, o produto tem potencial para ser utilizado. A fração do beneficiamento contendo os elementos magnéticos e ferromagnesianos pode ser utilizada na indústria cerâmica de revestimento (por via úmida), e porcelanatos, que não necessita de base branca. Os produtos das classes granulométricas e/ou dos diferentes estágios das separações, onde foi possível a retirada apenas parcial dos minerais ferromagnéticos (maior parte do volume), também poderão ser utilizados como fundentes na indústria cerâmica (via úmida e de porcelanato), com graus de nobreza variando de acordo com a quantidade de elementos cromóforos. As frações com granulação apropriada e teores de elementos cromóforos relativamente baixos também poderão ser utilizadas, como colorantes e nucleantes, nas indústrias de vidro de garrafa ou de vidros coloridos.

\section{AGRADECIMENTOS}

Ao CNPq (Processos PDJ 500301/2010-7 e PQ 304535/2011-7), pelas bolsas e auxílio concedido, e à Endeka Ceramics, pela realização de ensaios e apoio técnico. 


\section{REFERÊNCIAS BIBLIOGRÁFICAS}

BAUCIA Jr, J.A.; KOSHIMIZU, L.; GILBERTONI, C.; MORELLI, M.R. 2010. Estudo de fundentes alternativos para uso em formulações de porcelanato. Cerâmica, 56: 262-272.

BRAGA, P.F.A.; SAMPAIO, J.A.; LEAL FILHO, L.S. 1998. Estudos de Beneficiamento de Feldspato em Rochas Alcalinas. In: ABM, ENCONTRO NACIONAL DE TRATAMENTO DE MINÉRIOS E METALURGIA EXTRATIVA, 17, Águas de São Pedro, SP, Anais, 509-518.

BROTZU, P.; BARBIERI, M; BECCALUVA, L.; GARBARINO, C.; GOMES, C.B.; MACCIOTTA, G.; MELLUSO, L.; MORBIDELLI, U.; RUBERTI, E.; SIGOLO, J.B.; TRAVERSA, G. 1992. Petrology and geochemistry of the Passa Quatro alkaline complex, southeastern Brazil. Journal of South American Earth Sciences, 6(4): 237-252.

CHIESSI, C.M. 2004. Tectônica cenozoica do Maciço Alcalino de Passa Quatro (SP-MGRJ). Instituto de Geociências, Universidade de São Paulo, São Paulo, Dissertação de Mestrado, $116 \mathrm{p}$

CPRM - COMPANHIA DE PESQUISA DE RECURSOS MINERAIS. 2003. Informe de recursos minerais, 1 - diretrizes e especificações. CPRM, Rio de Janeiro, 200 p.

FRANÇA, S.C.A.; SAMPAIO, J. 2002. Obtenção de Feldspato a Partir de Finos de Pedreira de Nefelina Sienito e Utilização como Insumo para a Indústria Cerâmica. In: ABM, ENCONTRO NACIONAL DE TRATAMENTO DE MINÉRIOS E METALURGIA EXTRATIVA, 19, Recife, PE, Anais, 651-656.

GUILLET, R.G. 1994. Nepheline Syenite. In: D.D. Carr (ed.) Industrial Minerals And Rocks, $6^{\text {th }}$ Edition, Littleton, Colorado, Society for Mining, Metallurgy, and Exploration, Inc., p. 711-730.

HARBEN, P.W. 1995. The industrial minerals handybook II. Metal Bulletin, London, 253 p.

MOTTA, J.F.M.; COELHO, J.M.; JUNIOR, M.C.; ZANARDO, A.; TANNO, L.C. 2002. Raw materials for porcelainized stoneware tiles ceramic bodies in Brazil. Tile \& Brick International, 18(6): 358-363.

SIGOLO, J.B. 1988. As formações bauxíticas lateríticas do maciço alcalino de PassaQuatro MG: sua evolução micromorfológica, geoquímica e as implicações do relevo. Instituto de Geociências, Universidade de São Paulo, São Paulo, Tese de Doutorado, 186 p.

\section{Endereço dos autores:}

Carolina Del Roveri e Fabiano Cabañas Navarro - Núcleo de Engenharia de Minas, Instituto de Ciência e Tecnologia, Universidade Federal de Alfenas, Campus Avançado de Poços de Caldas, Rodovia José Aurélio Vilela, 11.999 (BR 267, Km 533), Cidade Universitária, CEP: 37.715-400, Poços de Caldas, MG, Brasil.E-mails: carolina.roveri@unifal-mg.edu.br, fabiano.navarro@unifal-mg.edu.br

Letícia Hirata Godoy, Antenor Zanardo e Maria Margarita Torres Moreno - Departamento de Petrologia e Metalogenia, Instituto de Geociências e Ciências Exatas, Universidade Estadual "Júlio de Mesquita Filho", Campus de Rio Claro, Avenida 24A, 1515, Bela Vista, CEP: 13.506-900, Rio Claro, SP, Brasil. E-mails: azanardo@rc.unesp.br, mmoreno@rc.unesp.br, godoylh@rc.unesp.br

Luciano Luis da Silva - Endeka Ceramics, Av. Ministro Roberto Cardoso Alves, 1351, Núcleo Industrial, CEP: 13.849-212, Mogi Guaçu, SP, Brasil.E-mail: luciano.silva@endekaceramics.com

Artigo submetido em 27 de junho de 2013, aceito em 19 de julho de 2014. 